\title{
NGFAST: A SIMULATION MODEL FOR RAPID ASSESSMENT OF IMPACTS OF NATURAL GAS PIPELINE BREAKS AND FLOW REDUCTIONS AT U.S. STATE BORDERS AND IMPORT POINTS
}

\author{
Edgar C. Portante \\ Brian A. Craig \\ Stephen M. Folga \\ 9700 South Cass Avenue \\ Argonne National Laboratory \\ Argonne, IL 60439, U.S.A.
}

\begin{abstract}
This paper describes NGfast, the new simulation and impact-analysis tool developed by Argonne National Laboratory for rapid, first-stage assessments of impacts of major pipeline breaks. The methodology, calculation logic, and main assumptions are discussed. The concepts presented are most useful to state and national energy agencies tasked as first responders to such emergencies. Within minutes of the occurrence of a break, NGfast can generate an HTML-formatted report to support briefing materials for state and federal emergency responders. Sample partial results of a simulation of a real system in the United States are presented.
\end{abstract}

\section{INTRODUCTION}

High-pressure interstate pipeline systems, carrying large volumes of natural gas (NG) over long distances, crisscross the United States, transporting gas from production fields and import points to consumers nationwide. A pipeline break, especially near the upstream origin point (i.e., pipeline origin point near production fields), could have significant, widespread impacts on downstream consumers and could affect multiple states, sending an entire region into chaos or "emergency mode." Moreover, interdependent infrastructures, such as the electric power sector, are often directly affected because outputs of NG-fired generating units could be significantly curtailed, which could eventually lead to a power supply deficiency in the electric power sector (PCCIP 1997). Because the Department of Energy (DOE) has limited the time for generating briefing materials for the Executive Office during such catastrophic events, an urgent need has emerged for fastturnaround tools that can quickly estimate the impact of pipeline breaks in both quantitative and qualitative terms. Argonne National Laboratory is experienced in perform- ing NG and petroleum systems analyses for this type of DOE-sponsored, multi-laboratory-supported endeavor.

\section{NGfast CAPABILITIES}

\subsection{Analysis and Data Retrieval Capabilities}

Argonne designed NGfast (written in C Sharp language) to be used as both an impact analysis tool and an information retrieval tool. When used as an impact analysis tool, given the name of the affected pipeline, the location of the break, and the month the event occurred, it provides:

- A quantitative estimate (tabular) of the impacts to downstream markets

- A graphic overview of impacts, and, thus, insights into possible restoration strategy options

- Options to implement mitigating measures

- An estimate of the net impact after application of mitigation measures (e.g., load shed, states affected, electric megawatts lost

Furthermore, NGfast has the capability of handling multiple breaks involving multiple pipelines across a number of states (Figure 1).

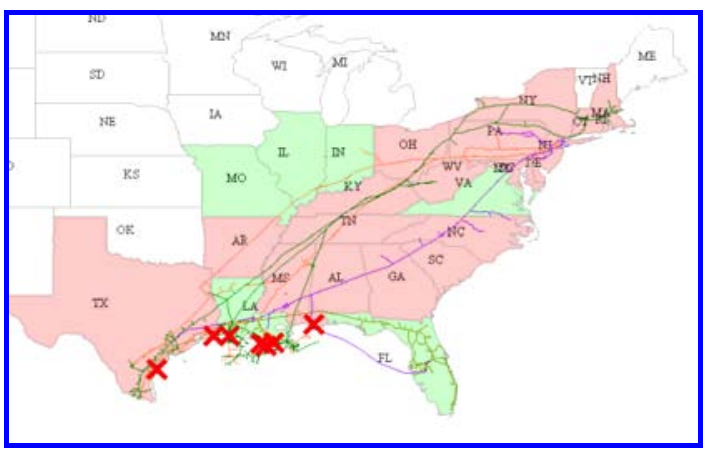

Figure 1: Actual graphical NGfast output (" $\mathrm{X}$ " indicates the location of a pipeline break. Affected states are shown in pink.) 
When used as an information retrieval tool, given the name of the pipelines of interest and the month the event occurred, it provides the following pre-disruption information:

- Information on normal systems operations, including:

- Average NG flow and direction of flow at the U.S. state border points

- Pipeline capacity at the U.S. state border points

- System structure (i.e., commodity flow connectivity) from source to end users, including:

- States and local distribution companies (LDCs) served by interstate pipelines

- Configuration of pipelines at U.S. state border points (e.g., number of pipelines, pipeline size)

- Demand per customer type (e.g., residential, commercial) within each LDC

- Spare mitigating capacity information for each state traversed by pipelines of interest, including:

- All pipelines delivering to and receiving gas from the states

- Underground storage (UGS) facilities

- Liquefied natural gas (LNG) storage facilities

- Production capacities

\subsection{U.S.-wide Tabular and Spatial Database}

The NGfast tool is a national model that includes data on more than 80 interstate pipelines, over 1,800 LDCs, and nearly 800 state border points. These data represent approximately $95 \%$ of existing pipelines, about $90 \%$ of existing LDCs, and $100 \%$ of known border crossings. NGfast also contains a database on the technical characteristics and monthly activities of UGS facilities and LNG and production fields. The state border database is the foundational information of the model. NGfast includes data on border points from nearly every state in the contiguous United States. A state border point contains useful information such as magnitude and direction of flow, sending and receiving pipelines, size and capacity of the pipelines, and longitude and latitude of the border point.

All of the data incorporated in NGfast were obtained from publicly accessible sources. All databases supporting the model are in Microsoft Access format. Assigned "primary keys" set up the tables for a dynamic relational computation. Spatial databases in shape files are used for displaying pipeline routes, state border points, and state boundaries via the graphical user interface (GUI) (see Tables 1 and 2).
Table 1: Data sets supporting NGfast.

\begin{tabular}{|l|l|}
\hline Name of Data Set & \multicolumn{1}{|c|}{ Information Content } \\
\hline State Border & $\begin{array}{l}\text { Location, average annual flow, } \\
\text { pipeline capacity, number of } \\
\text { pipelines, size of each pipeline, } \\
\text { sending and receiving pipeline } \\
\text { names, etc. }\end{array}$ \\
\hline Pipeline to LDC & $\begin{array}{l}\text { Relates each of the 80 or so } \\
\text { pipelines to all LDCs they serve, } \\
\text { including direct-connect loads in } \\
\text { all states they traverse }\end{array}$ \\
\hline LDC Load Classes & $\begin{array}{l}\text { Residential, commercial, indus- } \\
\text { trial, electrical gas use per LDC }\end{array}$ \\
\hline $\begin{array}{l}\text { UGS Activities and } \\
\text { Characteristics }\end{array}$ & $\begin{array}{l}\text { Location, working storage, max- } \\
\text { imum deliverability, and state- } \\
\text { level monthly injections and } \\
\text { withdrawal }\end{array}$ \\
\hline $\begin{array}{l}\text { LNG Facilities and } \\
\text { Characteristics }\end{array}$ & $\begin{array}{l}\text { Location, working storage, max- } \\
\text { imum deliverability, and unit- } \\
\text { level monthly injections and } \\
\text { withdrawal }\end{array}$ \\
\hline $\begin{array}{l}\text { Production } \\
\text { Profile }\end{array}$ & $\begin{array}{l}\text { State-level monthly marketed } \\
\text { production output and maximum } \\
\text { output }\end{array}$ \\
\hline
\end{tabular}

Table 2: Spatial data sets supporting NGfast.

\begin{tabular}{|l|l|}
\hline \multicolumn{1}{|c|}{ Name of Data Set } & \multicolumn{1}{|c|}{ Information Content } \\
\hline State Border Points & $\begin{array}{l}\text { Geolocation of state bor- } \\
\text { der natural gas meters }\end{array}$ \\
\hline Pipelines & $\begin{array}{l}\text { Geolocation and routes of } \\
\text { more than 80 pipelines }\end{array}$ \\
\hline State Boundaries & $\begin{array}{l}\text { State boundaries deline- } \\
\text { ated }\end{array}$ \\
\hline
\end{tabular}

\subsection{GUI, Spatial, and Tabular Outputs}

The GUI in NGfast is designed for easy "point, click, and analyze" use. You can point to any state border point, select a pipeline to "break," and execute a simulation run. The break could be total (100\% reduction) or partial, in which case you would enter a flow reduction number (in percent). Spatial output includes a picture of the simulated event (Figure 1), which shows the pipelines involved, the locations of the breaks, and the states affected. Tabular output includes detailed inflow-outflow tables that show values for both preand post-disruption conditions. All reports and spatial and tabular results are generated in HTML (Hypertext Markup Language) format. A summary tabular result is automatically generated for every run. The summary table includes the following information (Figure 2):

- Amount of gas withheld (lost) 
- States affected

- LDCs affected per state

- Load shed per customer class per LDC

- Number of customers affected

- Megawatts of electric power plants affected

- Alternative NG supply sources

$\begin{array}{lc}\text { View Tabular Results } & \\ \text { Disrupted Pipeline: } & \text { ABC Gas Transmission Co. } \\ \text { Number of States Affected } & 7 \\ \text { Number of LDCs Affected. } & 15 \\ \text { Total MMctD lost: } & 1541.226 \\ \text { Total MW lost } & 878.1553 \\ \text { Total Customers lost } & 940242\end{array}$

\section{A. MMefD Load Shed per affected state}

\begin{tabular}{|c|c|c|c|c|c|c|}
\hline \multicolumn{5}{|c|}{ MaMefD Shed } & \multirow[b]{2}{*}{ Total } & \multirow[b]{2}{*}{ \% Reduction } \\
\hline State & Res & Com & Ind & Dec & & \\
\hline $\mathrm{TN}$ & 8.4723 & 4.6543 & 12.2988 & 0 & 25.4254 & $100 \%$ \\
\hline NN & 150.7685 & 381.441 & 89.2732 & 2141.8288 & 763.3115 & $6844 \%$ \\
\hline $\mathrm{PA}$ & 1331 & 109.4004 & 290.777 & 747.4625 & 448.9708 & $39.94 \%$ \\
\hline NYY & 0 & 150.8258 & 0 & 0 & 150.8258 & $27.35 \%$ \\
\hline$\underline{\mathrm{DE}}$ & 0 & 0 & 0 & 21.466 & 21.466 & $23.34 \%$ \\
\hline $\mathrm{MD}$ & 0 & 0 & 0 & 0 & 0 & $\phi \%$ \\
\hline wV & 0 & 0 & 0 & 0 & 0 & $0 \%$ \\
\hline
\end{tabular}

\section{B. MW Shed per state}

$$
\begin{array}{|l|r|r|}
\hline \text { State } & \text { Total MW } & \% \text { Reduction } \\
\hline \text { DE } & 89.4415 & 63.33 \% \\
\hline \text { MD } & 0 & 0 \% \\
\hline \text { NJ } & 590.9535 & 100 \% \\
\hline
\end{array}
$$

Figure 2: Summary of NGfast analysis report output from a simulation run on an actual pipeline (Note: The company name is deleted to maintain confidentiality. Users "click" the state of interest to see details of pre- and postdisruption loading conditions of LDCs within the state).

\section{SIMULATION METHODOLOGY AND ASSUMPTIONS}

\subsection{Two Modes of Simulation}

The model has two modes of simulation: uncompensated and compensated. The former assumes that mitigation measures are not available and that the only way to balance supply and demand after a disruption is to shed load. The latter (i.e., compensated mode), however, provides the user with the option to activate and define a select set of mitigating actions to minimize the impact of the disruption. The uncompensated mode shows the worst-case scenario, whereas the compensated mode simulates the more realis- tic outcome. Mitigating measures include additional withdrawals from in-state UGS, LNGs, and production fields as well compensating flows from interconnected pipelines.

\subsection{Levels of Abstraction (Geographic Computational Granularity)}

The load shedding computation in NGfast is performed down to the LDC level. In other words, the load to be shed is allocated to residential, commercial, industrial, and electric power consumers according to a user-defined priority order. When a break occurs at the pipeline level, the volume lost is allocated to all downstream states affected and further to all affected LDCs within the state.

The computation of gas volumes from mitigating agents is performed at the state level. Under such an approach, all UGS facilities within the state are aggregated into a single fictitious composite unit; the output could be used to mitigate the loss of load within that state. The same principle applies to LNGs and production wells. However, compensating volumes from interconnecting pipelines are computed at the pipeline level. This concept is depicted in Figure 3.

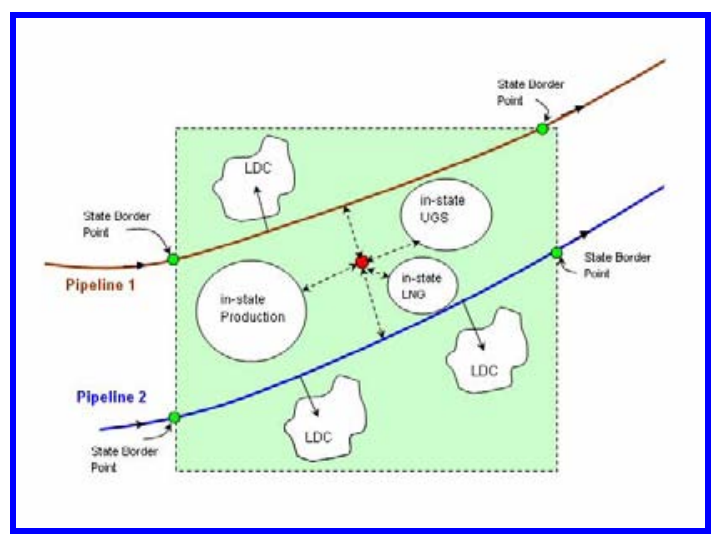

Figure 3: Computational granularity characterized by load shedding at the LDC level.

The red point shown in Figure 3 is called the model's "virtual point of confluence" (VPC). Within the state, four NG infrastructure components - UGS, LNG, production, and pipelines - are assumed to be directly connected to a VPC. Such a configuration makes the following operations possible via the VPC:

- Pipelines can exchange flows.

- UGS facilities can exchange flows with pipelines.

- LNG can be injected into pipelines.

- Production facilities can inject to pipelines.

Figure 3 also shows that each state border point is associated with a unique set of pipelines, and that each pipeline, in turn, is associated with a specific set of LDCs. 


\subsection{Calculation Logic - General Description}

NGfast is a linear model that uses a progressive forward pipeline ownership identification and flow quantification process to track lost flow volumes due to a pipeline break or curtailment in production. Heuristics are used to allocate load to be shed among affected LDCs and various consumer types within those LDCs. Heuristics are also applied to estimate spare capacity from compensating pipelines, UGS facilities, LNG facilities, and production fields (McAllister 1988). The calculation starts at the upstream state most affected by the break and proceeds progressively toward the terminal (most downstream) states. The special structure of the state border database (i.e., "from-state" and "to-state" fields) allows the calculation method to proceed following the flow of gas along the pipeline, analyzing each state in sequence as it is traversed by the pipeline. Figure 4

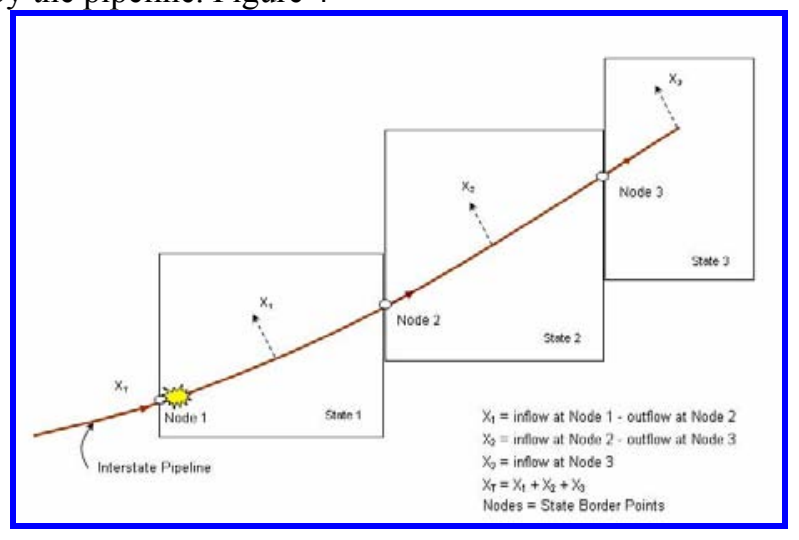

Figure 4: Forward flow and delivery quantification process. illustrates the forward flow quantification process for a simple single pipeline system traversing several states.

Under the uncompensated mode, when a state border node of a specific pipeline is assumed disrupted, the flow volume through that node (in millions of cubic feet per day $[\mathrm{MMcf} / \mathrm{d}])$ is assumed lost. If the pertinent line traverses several states downstream of the disruption point, a multiplestate scenario computation must be performed, and the impacts on all the downstream states must be analyzed.

The forward quantification logic operates by repeatedly applying a recursive flow balance equation to each affected state. The recursive equation simply states:

State Delivery $=$ Inflow - Outflow

$(\mathrm{MMcf} / \mathrm{d})$

Because the states traversed by the affected pipeline are in cascade, the output of the upstream state becomes the input into the immediately downstream state.

\subsection{Relational Database Operation}

Identification of the disruption points starts with the state border data set where the delivering (affected) pipeline is identified, and the magnitude of flow is defined. A series of relational database calculations then ensues to determine the states affected, the affected LDCs in each state, and the corresponding loads in each LDC. Once the magnitude of lost loads is determined for each state, the mitigating measures logic is triggered so that corrective actions from UGS, LNG, production wells, and interconnectting pipelines are set into play. Figure 5 illustrates the relational operation for the compensated case. Operation for uncompensated case would involve only the first three lower boxes.

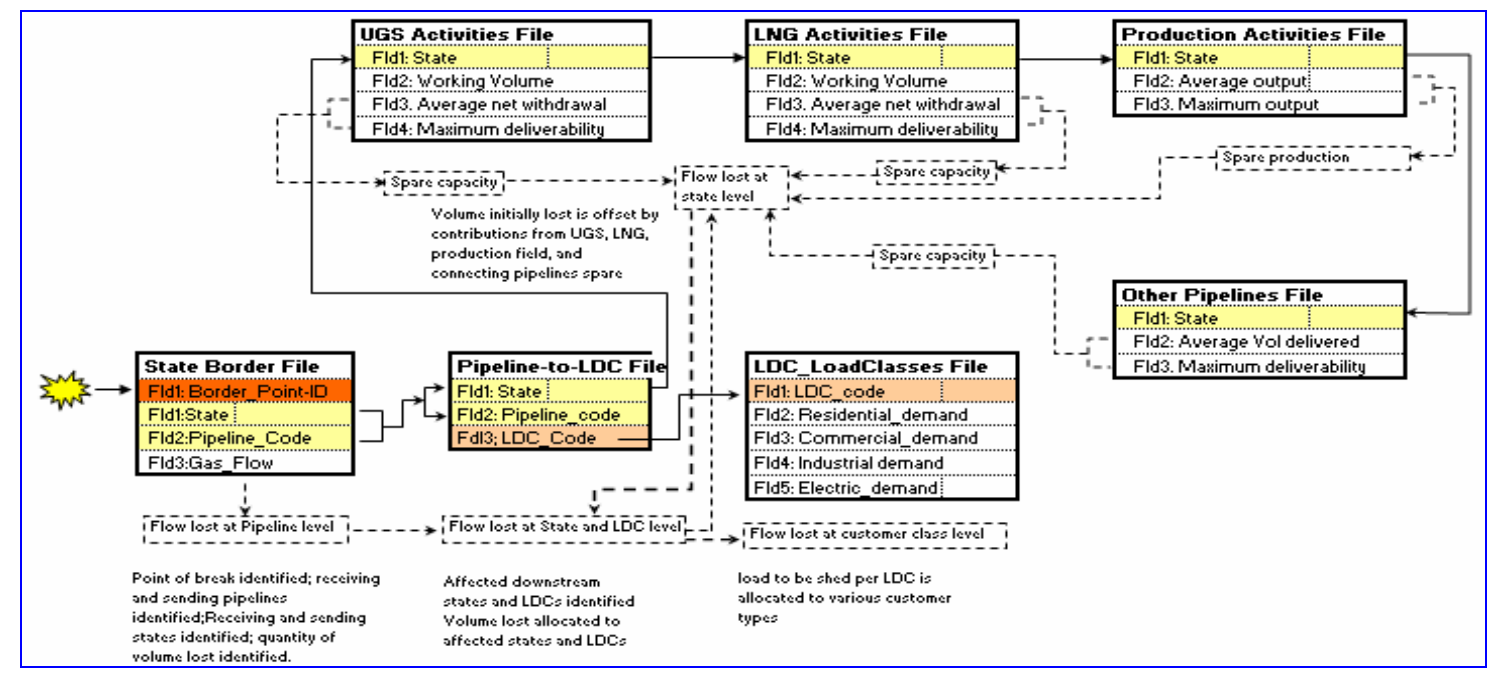

Figure 5: Relational database operation under a compensated simulation mode. 


\subsection{Varying Pipeline Configuration Complicates Forward Flow Quantification Process}

The NGfast calculation logic was formulated to handle the complications presented by varying configurations of the 80 or so interstate pipelines included in the model. Below is the range of complicated cases encountered during the logic development process. Note that a pipeline disruption need not be a break; it could simply be a reduction in flow because of changes in pressure levels (e.g., due to outage of a compressor upstream).

Case 1 Simple single-line system passing through several states. Configuration is similar to that depicted in Figure 4. This case represents the simplest pipeline configuration: the forward flow quantification process procee-

ds without difficulty. A uniform reduction factor is applied to each of the in-state deliveries by the pipeline as well as the interstate flows.

Case 2 Single-line multiple interstate feed (Figure 6). In Case 2, which is very similar to Case 1, a uniform reduction factor is applied to each of the in-state deliveries by the pipeline as well as the interstate flows.

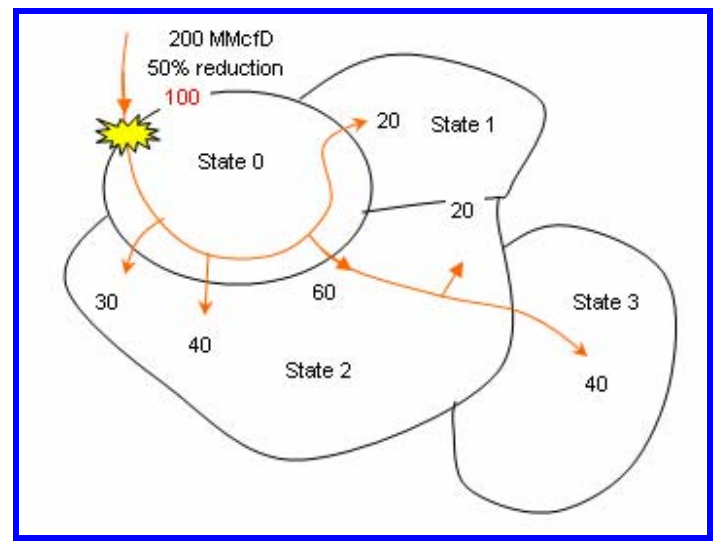

Figure 6: Pre-disruption flow values for Case 2 configuration.

Case 3 Multiple lines at state border and interconnection inside the state (Figure 7). Case 3 is more complicated than either Case 1 or 2 . The pipeline system runs through two parallel corridors as it enters state 3, merges at a point within the state, then breaks again into a number of corridors serving several downstream states.

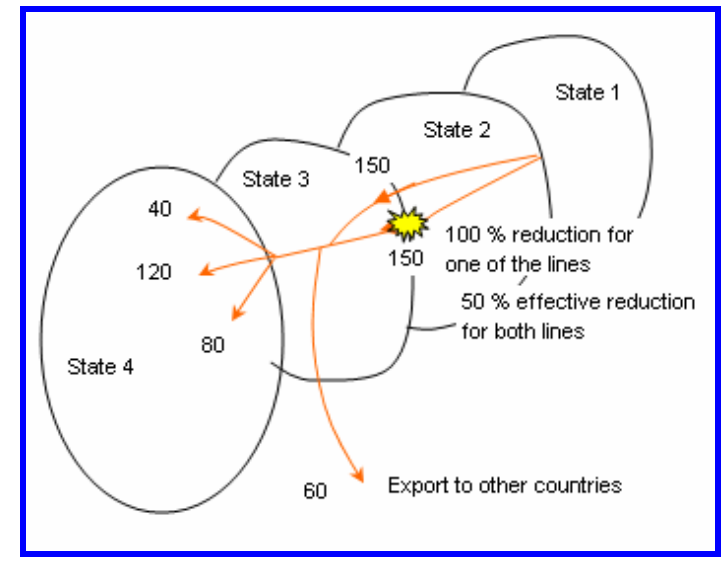

Figure 7: Pre-disruption flow (MMcf/d) for Case 3.

Case 4 Multiple lines at state border with no interconnection inside the state (Figure 8). In Case 4, the analyst would need to draw a "connectivity schematic diagram" (shown as blue broken lines in Figure 8); this "network builder" feature is part of the GUI and makes the connectivity construction task easy and convenient. The connectivity diagram helps to ensure that each inputside state border point identifies the appropriate outputside state border whose flow could be affected by the change in flow in the input-side state border point. Links in the connectivity schematic diagrams are called "lines of influence."

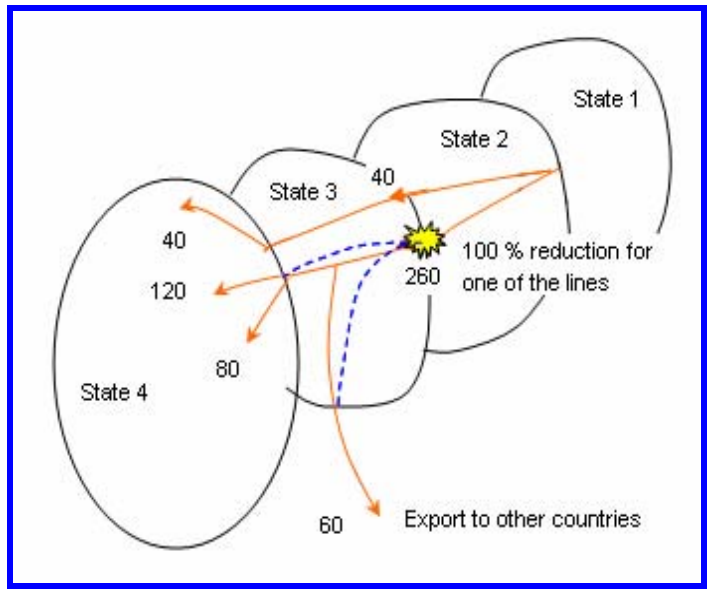

Figure 8: Pre-disruption flow (MMcf/d) for Case 4.

Case 5 Single or multiple lines with outgoing flow greater than incoming flow. In Case 5, the delivery to the state by the pipeline is zero (i.e., on a net flow basis), indicating that the LDCs within this state do not depend on the pipeline for their supply. 


\subsection{Compensating Action from Mitigation Sources}

Compensating actions can be selected and defined via the flexible Policy Editor Window (Figure 9). This window allows you to specify the implementation sequence of the mitigating measures and their magnitudes.

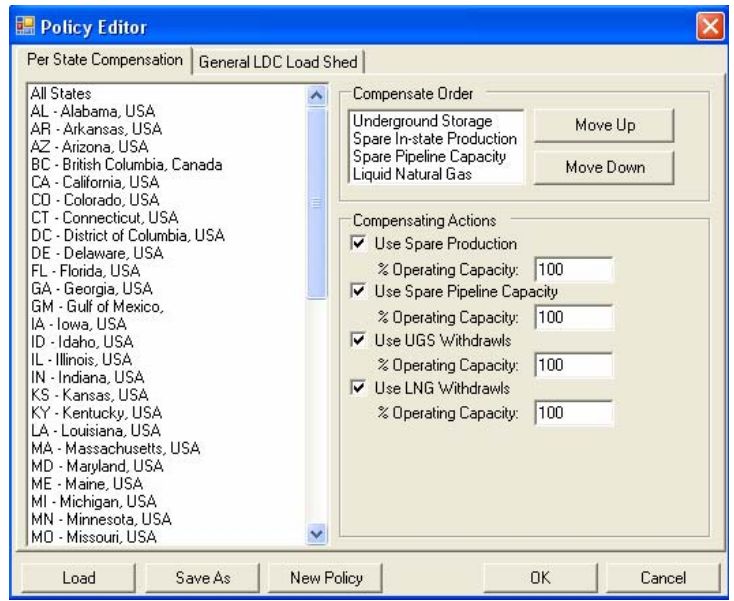

Figure 9: Policy Editor Window that defines the implementation sequence and magnitude of available mitigating measures

\subsubsection{Spare Capacity from Surviving Pipelines}

For the surviving, or compensating, pipelines, the following rules are observed:

Case 1 Outflow is less than inflow. The estimated compensating capacity for the state can be computed as follows:

Compensating Cap $=$

(inflow - outflow)/inflow * (pipeline capacity - inflow)

Case 2 Inflow is zero. If inflow is 0 , the compensating capacity is also 0 .

Case 3.Outflow is greater than inflow. If the inflowoutflow term is 0 or negative, the compensating capacity is also 0 .

Whenever the outflow is greater than the inflow, the net delivery into the state is 0 , and, from the perspective of the pipeline, the net flow is an injection or a receipt. In this case, there is only a receipt point (no delivery point), so even if the incoming capacity is large, the immediate state cannot use it because the state being considered does not have a delivery point.

\subsubsection{Contributions from UGS Facilities}

If the composite UGS is in injection mode during the disruption, the UGS should stop injecting, and gas volume intended for storage should be used to mitigate shortfall. Thus, it is assumed that the UGS cannot reverse flow quickly but can stop injection abruptly. If the UGS is in withdrawal mode, the compensating withdrawal rate is set equal to the UGS's deliverability (i.e., maximum rated outflow) less its net withdrawal for the month (EIA 2002).

\subsubsection{Contributions from LNG}

LNG facilities are assumed to be in injection mode during all non-winter months and in withdrawal mode during the winter months (i.e., November through March). During the winter months, LNG is assumed capable of releasing up to its rated output (gasification rate).

\subsubsection{Contributions from Production Fields}

Spare production rate is calculated as the difference between the maximum output of the fields during all 12 months of the year, minus the production level during the month when the postulated disruption occurs. This spare capacity could be applied to any residual unbalanced volume (load) resulting from the pipeline break.

\section{A CASE STUDY APPLICATION}

\subsection{Study Description}

NGfast was used in a recent study (March 2007) to estimate the impact of a postulated flow reduction in a real interstate pipeline system (fictitious name: ABC PL Co.) crossing the Savannah River at the South Carolina Georgia border as shown in Figure 10. The reduction in flow was necessitated by an assumed flooding of the Savannah River due to a breach in a large dam upstream of the river.

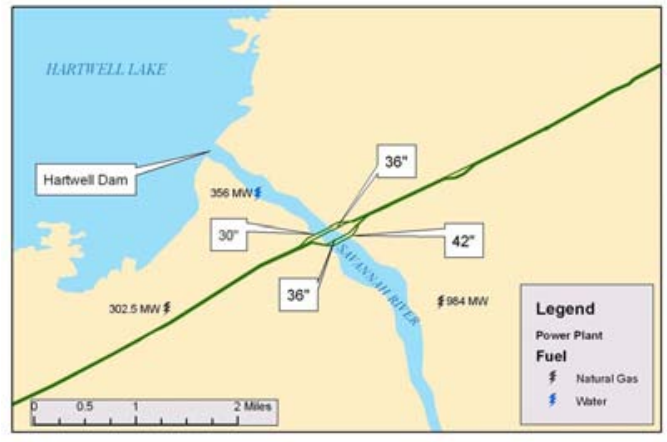

Figure 10: The segment of interstate pipeline system affected by the postulated flooding. 
The scenario assumed that the affected pipeline segments are at the river bottom and are weighted. It was also assumed the pipeline operation personnel considered lowering pressure to reduce pipeline stresses. A flow reduction of $25 \%$ was subsequently assumed appropriate to meet this objective. The geographical location of the flow reduction point is shown in Figure 11. The characteristics of the pipeline segment where the flow reduction is effected are summarized in Figure 12.

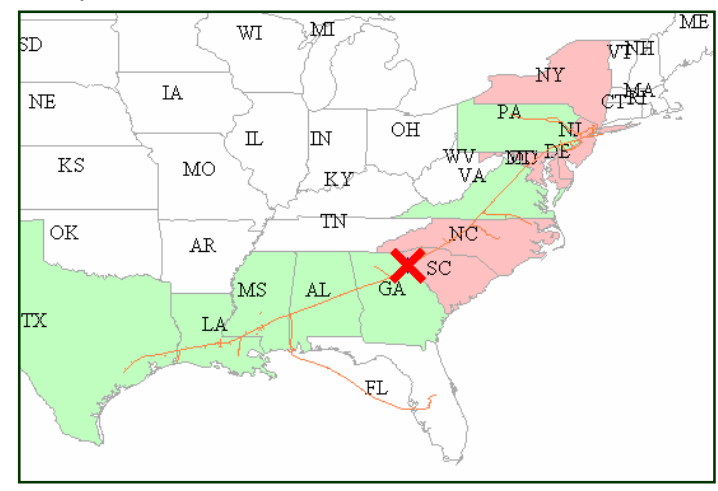

Figure 11: Postulated point of flow reduction is indicated by a red " $\mathrm{X}$ " sign.

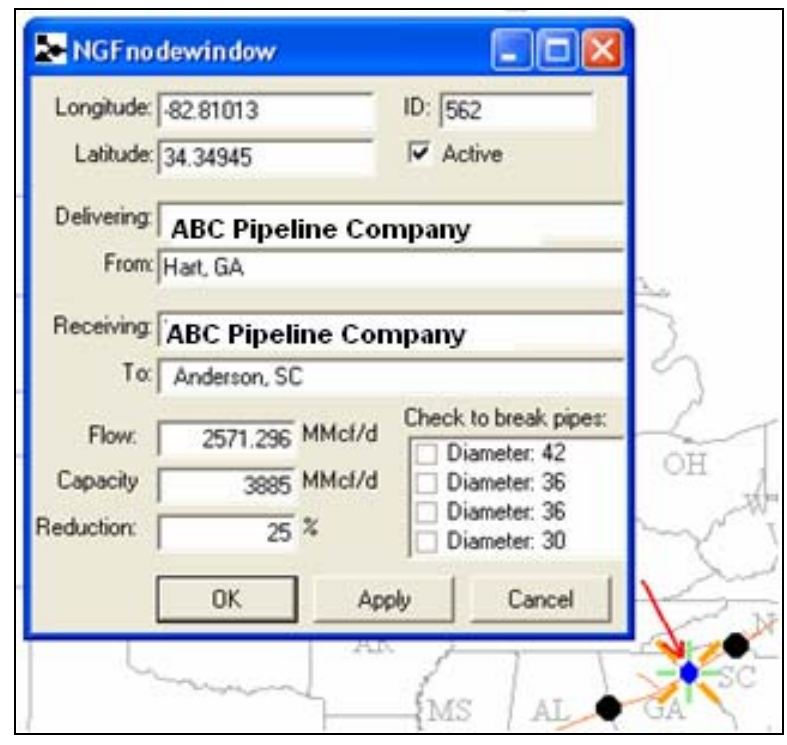

Figure 12: NGfast GUI Window showing characteristics of the affected line segment.

\subsection{Results of the Simulations}

The simulation results for the uncompensated and compensated cases as generated by NGfast are summarized in Table 4. Tables $5-8$ show results associated with the uncompensated case. Overall, the results show that with im- plementation of mitigation measures, a $25 \%$ reduction in flow would have no impact on the downstream markets.

The uncompensated scenario may be considered the worst unrealistic scenario with a probability of occurrence of almost nil. Because of the presence of UGSs in some of the affected states and the interconnected nature of the NG interstate pipelines, there are always optionseffective options - to mitigate the impacts resulting from a pipeline break or flow reduction.

Table 4: Summary of NGfast simulation results for the uncompensated and compensated Cases.

\begin{tabular}{|l|c|c|}
\hline \multicolumn{1}{|c|}{$\begin{array}{c}\text { Impact Met- } \\
\text { rics }\end{array}$} & Uncompensated & Compensated \\
\hline $\begin{array}{l}\text { Number of } \\
\text { states affected }\end{array}$ & 6 & 6 \\
\hline States Affected & $\begin{array}{c}\text { SC, NC, DE, NJ, } \\
\text { NY, MD }\end{array}$ & 0 \\
\hline $\begin{array}{l}\text { Number of } \\
\text { LDCs affected }\end{array}$ & 29 & 0 \\
\hline $\begin{array}{l}\text { Total flow lost } \\
\text { MMcf/d }\end{array}$ & 643 & 0 \\
\hline $\begin{array}{l}\text { Estimated total } \\
\text { MW capacity } \\
\text { lost }\end{array}$ & 1,600 & 0 \\
\hline $\begin{array}{l}\text { Estimated total } \\
\text { number of cus- } \\
\text { tomer lost }\end{array}$ & 21,600 & 0 \\
\hline
\end{tabular}

Table 5: Summary of load shed (in MMcf/d) per affected state for the uncompensated Case (Note: Res = residential; Com $=$ commercial; Ind = industrial; Elec = Electric; Red $=$ reduction).

\begin{tabular}{|l|r|r|r|r|r|c|}
\hline State & Res & Com & Ind & Elec & Total & $\begin{array}{c}\text { \% } \\
\text { Red }\end{array}$ \\
\hline NJ & 0 & 1.36 & 58.03 & 155.97 & 215.36 & $14.8 \%$ \\
\hline NY & 0 & 55.82 & 46.26 & 94.83 & 196.91 & $17.7 \%$ \\
\hline NC & 0.02 & 0.02 & 66.67 & 91.94 & 158.66 & $26.6 \%$ \\
\hline SC & 0 & 0 & 15.29 & 23.13 & 38.42 & $16.7 \%$ \\
\hline MD & 0 & 0 & 17.90 & 1.56 & 19.47 & $7.0 \%$ \\
\hline DE & 0 & 0 & 0 & 13.97 & 13.97 & $15.2 \%$ \\
\hline
\end{tabular}

Table 6: Summary of MW shed per affected state for the uncompensated case.

\begin{tabular}{|c|r|}
\hline State & \multicolumn{2}{|c|}{ Total MW } \\
\hline NJ & 649.87 \\
\hline NY & 395.13 \\
\hline NC & 383.10 \\
\hline SC & 96.39 \\
\hline DE & 58.23 \\
\hline MD & 6.51 \\
\hline
\end{tabular}


Table 7: Summary of flow (MMcf/d) lost per affected state for the uncompensated case.

\begin{tabular}{|c|r|}
\hline State & Flow (MMcf/d) Lost \\
\hline NJ & 215.36 \\
\hline NY & 196.91 \\
\hline NC & 158.66 \\
\hline SC & 38.42 \\
\hline MD & 19.47 \\
\hline DE & 13.97 \\
\hline
\end{tabular}

Table 8: Summary of number of customer shed per affected state for the uncompensated case.

\begin{tabular}{|l|r|r|r|r|r|}
\hline State & \multicolumn{1}{|c|}{ Res } & \multicolumn{1}{c|}{ Com } & \multicolumn{1}{c|}{ Ind } & \multicolumn{1}{c|}{ Elec } & \multicolumn{1}{c|}{ Total } \\
\hline NY & 0 & 15,848 & 739 & 5 & 16,592 \\
\hline NJ & 0 & 669 & 2,489 & 334 & 3,492 \\
\hline NC & 124 & 17 & 836 & 15 & 993 \\
\hline MD & 0 & 0 & 401 & 7 & 408 \\
\hline SC & 0 & 0 & 101 & 5 & 106 \\
\hline DE & 0 & 0 & 0 & 0 & 0 \\
\hline 4 & 0 \\
4.3 & 0 & 0 & 0
\end{tabular}

The entire data set used for the simulation is quite extensive and would require more space than this paper would allow. For this reason, only the relevant input data is presented. Table 9 summarizes the state border point information associated with ABC PL Co.

Table 9: Description of State Border Points associated with ABC PL Co. from GA to NY (Note: Del = Delivering; Rec =receiving; Cap = capacity ).

\begin{tabular}{|l|l|l|l|r|r|}
\hline $\begin{array}{l}\text { Del } \\
\text { PL }\end{array}$ & $\begin{array}{l}\text { State } \\
\text { From }\end{array}$ & $\begin{array}{l}\text { Rec } \\
\text { PL }\end{array}$ & $\begin{array}{l}\text { State } \\
\text { To }\end{array}$ & $\begin{array}{l}\text { Cap } \\
\text { (MMcf/D) }\end{array}$ & $\begin{array}{l}\text { Ave Flow } \\
\text { (MMcf/D) }\end{array}$ \\
\hline ABC & GA & ABC & SC & 3,885 & 2,571 \\
\hline ABC & SC & ABC & NC & 3,692 & 2,418 \\
\hline ABC & NC & ABC & VA & 2,870 & 1,783 \\
\hline ABC & VA & ABC & NC & 400 & 0 \\
\hline ABC & VA & ABC & NC & 20 & 0 \\
\hline ABC & VA & ABC & MD & 2,100 & 1,870 \\
\hline ABC & MD & ABC & PA & 2,050 & 1,789 \\
\hline ABC & PA & ABC & DE & 76 & 61 \\
\hline ABC & PA & ABC & NJ & 1,432 & 969 \\
\hline ABC & PA & ABC & NJ & 358 & 242 \\
\hline ABC & PA & ABC & NJ & 885 & 599 \\
\hline ABC & NJ & ABC & PA & 21 & 0 \\
\hline ABC & NJ & ABC & NY & 110 & 75 \\
\hline ABC & NJ & ABC & PA & 400 & 0 \\
\hline ABC & NJ & ABC & PA & 200 & 0 \\
\hline ABC & NJ & ABC & PA & 1,300 & 0 \\
\hline ABC & NJ & ABC & NY & 362 & 247 \\
\hline ABC & NJ & ABC & NY & 190 & 130 \\
\hline ABC & NJ & ABC & NY & 606 & 413 \\
\hline
\end{tabular}

\section{CONCLUSIONS}

NGfast is a rapid-response tool intended to assess impacts of a major pipeline break. NGfast maximizes the use of publicly available information to develop relatively straightforward, but insightful, analysis tools. Within minutes of a break, NGfast can generate an HTMLformatted report to support briefing materials for state and federal emergency responders. NGfast is ideal for generating quick, first-stage response.

\section{ACKNOWLEDGMENTS}

The authors wish to acknowledge the support of the Infrastructure Assurance Center of Argonne National Laboratory for funding the initial development of NGfast. The authors also wish to thank the following members of the Argonne NG analysis team for their significant contributions: James Peerenboom, Ronald Fisher, Michael McLamore, Shabbir Shamsuddin, Jason Bodily, Julie Muzzarelli, and Debra Fredrick.

\section{REFERENCES}

EIA (Energy Information Administration). 2002. The Basics of Underground Natural Gas Storage, U.S. Department of Energy. Available via <http://tonto.eia.doe.gov/FTPROOT/na tgas/storagebasics.pdf> [accessed July 2006].

McAllister, E. W. 1988. Pipeline Rules of Thumb Handbook. 2nd ed. Houston, Texas:Gulf Publishing Company.

PCCIP (President's Commission on Critical Infrastructure Protection). 1997. Issues Report on the Oil and Natural Gas Infrastructure, The Energy Team, July.

\section{AUTHOR BIOGRAPHIES}

EDGAR C. PORTANTE is an energy systems engineer at Argonne National Laboratory. His research interests include performance and vulnerability assessments of energy systems, including electric power and natural gas. Portante earned a Masters in Electrical and Computer Engineering from Illinois Institute of Technology, a Master of Management degree from Asian Institute of Management, and an M.S. in Power Systems Engineering from the University of the Philippines. His e-mail address is <ecportantedanl.gov>.

BRIAN A. CRAIG is a software engineer at Argonne National Laboratory. His work focuses primarily on the development of computer simulation models for various energy and supply chain systems. Craig earned a B.S. and 
an M.S. in Computer Science from North Central College in Illinois. His e-mail address is $\langle$ bcraigeanl. gov $>$.

STEPHEN M. FOLGA has worked at Argonne National Laboratory for 16 years and focuses his research on natural gas and petroleum systems modeling and analysis. $\mathrm{He}$ is the manager of the Energy Systems Analysis and Assessment branch of the Infrastructure Assurance Center at Argonne. Folga earned a Ph.D. in Gas Engineering and a B.S. in Chemical Engineering from Illinois Institute of Technology. His e-mail address is <sfolgaeanl.gov $>$. 